\title{
Generating Efficiency: Economic and Environmental Regulation of Public and Private Electricity Generators in Spain
}

\author{
Pablo Arocena \\ Universidad Pública de Navarra \\ and Centre for Management under Regulation, University of Warwick

\section{Catherine Waddams Price ${ }^{1}$} \\ Centre for Management under Regulation, University of Warwick \\ and Centre for Industrial Economics, University of Copenhagen
}

\section{July 1999}

\begin{abstract}
Economic regulation of firms with market power has placed increasing emphasis on incentive-based regulation such as price caps. We focus on the effect of regulation as distinct from ownership, and identify the effect of two different regulatory schemes on both publicly and privately owned Spanish electricity generators. Publicly owned generators were more efficient under cost of service regulation; private (but not public) firms responded to incentive regulation by increasing efficiency, bringing their productivity to similar levels. We introduce some novelty in modelling efficiency, including three pollutants and declared plant availability as outputs, and we test for the effect of environmental regulation in reducing pollutants.
\end{abstract}

Keywords: Price Cap Regulation, Total Factor Productivity, Electricity

JEL classification numbers: L51, L94, D24

We are grateful for many helpful comments received at an Industrial Economics workshop at the University of Warwick, at the Electricity in Europe in the 21st Century conference held in Paris in November 1998, at a Centre for Industrial Economics workshop and at the Design of Energy Markets and Environment conference in Copenhagen in May 1999. We thank the National Electricity Regulatory Commission in Spain for supplying data.

\footnotetext{
1 Corresponding author: Centre for Management under Regulation, Warwick Business School, University of Warwick, Coventry CV4 7AL, UK; tel (00) 441203 524506; fax (00) 441203 524965; email catherine.waddams@warwick.ac.uk
} 


\section{Introduction}

Economic regulation of firms with market power has undergone major reform in the past twenty years. The emphasis has shifted away from cost-plus regulation, where prices reflected the level of costs which firms had incurred, towards incentive based regulation systems such as price cap, sliding scale regulation, and yardstick competition. Such incentive regulation is in its early days in the US, particularly in the telecoms and energy industries, where it is being introduced to remedy high costs and inefficient input choice resulting from many years of cost-plus regulation. Price cap is one form of regulation with high-powered incentives: prices or revenues are capped so that the company can increase profits only by reducing its costs. Change from a cost of service system of regulation to a price cap incentive would therefore be expected to induce increased efficiency (Liston, 1993). However we would expect the effect to differ in the private and the public sectors.

In the UK, price cap regulation was introduced simultaneously with the transfer of firms from the public to the private sector. Much of the argument for this change in ownership was also on efficiency grounds - that companies would have greater incentives to reduce costs if they owned the residual profits, rather than having to return them to the Government as they had when nationalised. Price caps were seen primarily as a means of preventing monopoly exploitation, with the additional benefit of the desirable incentive properties outlined above (Littlechild, 1983). There have indeed been substantial cost reductions in UK industries privatised in the eighties and early nineties (Newbery and Pollitt, 1997, show this effect for electricity generation) but the coincidence of the change of ownership and the new regulatory system ${ }^{2}$ makes it difficult to distinguish the effects of each of these changes.

However at the same time as price caps were being introduced for many newly privatised British utilities, a similar reform was introduced in the Spanish electricity sector, with a change from a cost-plus type regulation to an incentive based scheme in 1988; the same reform was applied to firms (continuing) in both public and private sectors, with no change of ownership until much later, at the end of the period which we are considering. We are therefore able to examine the effect of a simultaneous change from cost-plus to incentive regulation on both private and public firms, in the context of a stable ownership structure.

We use data on inputs and outputs to calculate the Total Factor Productivity (TFP) change in the Spanish coal-fired generating plants over the 1984-1997 period. Since coal-based generation accounted for more than $40 \%$ of total electricity production in Spain during these ten years, the evaluation of the productivity gains in these plants gives us a valuable insight into how well this system performed. At the same time, given that the Spanish electricity industry was a mixed system of public and private ownership, the paper explores differences in behaviour and performance between public and private generators.

We use mathematical programming methods both to assess the evolution of the

\footnotetext{
${ }^{2}$ In the UK, electricity generation privatisation was accompanied by the introduction of some competition rather than explicit price caps, though price caps on pool prices were applied for two years in 1994-96.
} 
productive efficiency and to construct the Malmquist productivity index to compute and decompose the TFP change into the main components of productivity growth, namely technical efficiency change, differences in scale efficiency and technological change. This methodology is particularly useful to measure TFP growth in regulated environments, characterised by unavailability or distortions of cost and price information. However we depart from the standard use of inputs and outputs in assessing productivity in electricity generation, to better reflect the central despatching system used for generation in Spain and to include pollutants, and compare our results with the standard model.

The next section explains the background to the regulatory reform and the effect which we would expect it to have, leading to the formulation of the hypotheses which we test; section 3 explains the Malmquist indices and the novelty of our model; section 4 presents our data and main results, and section 5 compares these with alternative models; section 6 concludes.

\section{Background}

The Spanish electrical power industry is the fifth largest in the European Union with 43,551 MW of installed capacity and 162,180 MWh demanded in 1997 (REE, 1997). As Table 1 shows, the structure of generation is diverse, as a result of the endowment of natural resources and energy policy decisions made at the end of the 70's.

\section{[Table 1 about here]}

Spain has significant hydroelectric resources, which currently represent $38 \%$ of total installed capacity. However, because of variation in precipitation, there are substantial differences in hydro production between dry and wet years. During 19841997 average annual hydro generation accounted for around $20 \%$ of total output. Spain has practically no domestic reserves of petroleum and natural gas, coal being the only indigenous fossil fuel. Oil-based generation represented around $40 \%$ of the total production in 1974/76, but after the oil crises of 1973 and 1979, policy was to reduce dependence on external energy sources, leading to a construction programme of coal-fired and nuclear plants. Between 1974 and 1985 five nuclear reactors and twenty-one coal generating units came into operation. Coal-fired plants, built to increase consumption of domestic coal, generated $42 \%$ of total electricity production during the 1984-1997 period, while the contribution of oil fell virtually to zero by the end of the period.

From 1988 to 1998 the Spanish electricity industry was controlled by the "Marco Legal Estable" (hereafter MLE) or Stable Legal Framework. The MLE came into force at the beginning of 1988 , and constituted a new regulatory régime ${ }^{3}$, established by Royal Decree 1538/1987 of 11 December 1987, representing the culmination of a long reorganisation process which had started at the beginning of the eighties. The MLE replaced a régime based on a non-transparent, negotiated, cost of service regulation: the Ministry of Industry and Energy had approved tariffs designed to cover the costs which the firms declared. This type of regulation, negotiated behind closed doors, led

established by Royal Decree 1538/1987 of 11 December 1987 
to a situation which, years later, was described as "unbearable obscurity" by the current Chairman of the CNSE (Fernández-Ordónez, 1996). It is not surprising that this régime caused deep concern about the firms' levels of productive efficiency; a major objective of the 1988 reform was the introduction of incentive mechanisms to promote efficiency in the firms.

The MLE established "standard costs", which constituted the key feature of the regulatory régime. Each item required to supply power was allocated such a standard cost. These costs were established separately for generation and distribution, depending on the characteristics of the installation, and applied to each firm; they were determined regardless of the costs of any individual firm, and indeed without reference even to the average costs of the firms. Firms were allowed revenue based on these standard costs, irrespective of the actual costs which they incurred. The allowed costs were increased by the retail price index each year. There was no expected reduction in price as a result of potential efficiency gains, and so the firms had no temptation to try and manipulate costs to influence future allowed revenue levels ${ }^{4}$. In this sense it was a purer price cap than that applied to privatised industries in the UK where caps are reviewed at fixed intervals, and where the revised cap depends partly on the firms' own performances during the previous period ${ }^{5}$. In the Spanish system allowed revenue was determined exogenously: if the firm incurred lower (greater) costs than the standard costs, it kept (absorbed) the difference. The scheme thus exhibited the incentive properties of pure price cap regulation. Laffont and Crampes (1995) express doubts about the 'purity' of the cap, mainly on the grounds that it could distort managers' investment decisions. Our main focus is on a short-run model where capital is a fixed input, so this issue does not arise. However we also analyse long run efficiency, and discuss the implications of these doubts in the context of our results.

We would expect the application of an incentive scheme to have very different effects on private and public companies. Although there is literature on the relative efficiency of public and private firms (e.g. Caillaud et al, 1988, Vickers and Yarrow, 1988, Laffont and Tirole, 1993), we do not know of models which predict productive efficiency under different types of price cap, and so we give an outline here of what we would expect. The main difference between private and public sector firms concerns the objective function of the owners. In the private sector this is maximisation (or similar) of profits, while the public sector objective function would include other factors, in particular a negative weight on any subsidies required. Our prior assessment of the effect of different regulatory régimes on productive efficiency is based primarily on these differences in objectives.

Consider first the effect of the old régime of cost of service regulation, where each firm is virtually guaranteed reimbursement of its costs. Profit will not be increased by reductions in cost, and so the private company has no incentive to cut costs. If prices were determined by the cost level of the individual firm, then profits might be increased by reduced costs through their effect on prices and demand. But in the case

\footnotetext{
${ }^{4}$ Not until 1996 was an RPI-X formula introduced to adjust generation and distribution standard costs.

${ }^{5}$ Although such a price cap was not applied directly to generators in the UK (except, informally, for a brief period in the mid 'nineties) it has been used in several industries including other parts of the electricity industry
} 
we consider, where aggregate prices are set to cover the costs of electricity suppliers as a whole, and the costs of each generator reimbursed, the relation between costs and prices for any one firm is too tenuous to be relevant.

Similarly public companies cannot increase profits by reducing costs. But unlike their private counterparts, public owners are likely to attach a positive weight to lowering costs, because this reduces the reimbursement necessary within the cost of service regulation scheme, and relieves pressure on public funds. Therefore if the owners are equally effective at transmitting their objectives to managers, we would expect the direct interest which the public sector has in minimising the subsidy to be reflected in lower costs and greater productive efficiency in the public than in the private sector under cost of service regulation. This is consistent with de Fraja's (1993) suggestion that the public sector may be more efficient, and leads to our first hypothesis: that public companies are more efficient than private companies under cost of service regulation.

However the move to price cap regulation provides rather different incentives. Here firms retain any profit generated by cost reductions. Any increase in productive efficiency will increase profit; since prices are fixed by the level of the cap, cost reductions will not affect demand (assuming that the cap is binding). Profit is the only objective of the private firms, so there is a one-to-one relation between cost reductions and increases in the value of the objective function; in contrast profit maximisation may be only one of several objectives in the public sector, and so the relation between increased productivity and the objective function is diluted. We therefore expect price caps to increase efficiency in both sectors, but the effect to be greater, and quicker, in the private sector. Adjustment would be quicker amongst private firms not only because the relation between cost reductions and the objective function of the owners is more immediate. Two other factors would magnify this effect. If they are already less efficient they would have more ground to recover, and the control mechanisms for aligning managers' actions to owners' objectives may be stronger in the private than the public sector. Our second and third hypotheses follow, namely that productivity will grow more in private firms than in public firms when price cap regulation is introduced and that the private sector will operate more efficiently under this regulation system than their public counterparts.

The MLE was itself eventually replaced by further reforms. In April 1993 the Government approved a draft bill to introduce some general liberalisation measures in order to promote a higher degree of transparency and competition within the electricity market ${ }^{6}$. However the sector continued operating under the MLE until 31 December 1997. Approval of the new Electricity Law 54/1997, establishing the liberalisation of the sector from 1998 (see Arocena et al. 1998), replaced the Stable Legal Framework, and paved the way for privatisation. We restrict our analysis to the years immediately before and during the MLE; however we also test whether public firms anticipated privatisation by increasing their productivity (hypothesis 4) as has been observed elsewhere (see for example Waddams Price and Weyman-Jones, 1996).

\footnotetext{
${ }^{6}$ This first attempt at reform was delayed until December 1994, when the Electricity Law 40/1994 on the regulation of the National Electricity System was approved (see Kahn, 1996), but the majority of its proposals were never fully developed.
} 
As well as these four hypotheses we also examine two other aspects of the regulatory régime: whether or not capital is treated as a fixed input, since in effect there was very little capacity change during the period concerned; and how effective the environmental regulation was in constraining the production of pollutants. To assess the effect of our model specification we also compare our reference model with conventional formulations in electricity generation.

\section{The measurement of efficiency performance and productivity change}

One performance measure of any economic unit is partial productivity indices or output/input ratios. However most technologies employ several inputs and produce different outputs so that improvement in a partial productivity index might be explained by input-output substitution, and not necessarily by an efficiency improvement in input usage or output production. Likewise, the measurement of productive efficiency is often orientated in some way, in the sense that either inputs or outputs are considered exogenous or outwith the control of the firm. An input oriented efficiency measure indicates the ability of one economic unit to reduce the input consumption for a given level of output. Conversely, output orientation measures the ability of an economic unit to increase output for a fixed level of inputs. Which is adopted depends on which best describes the managers' behaviour. In some circumstances simultaneous output maximisation and input minimisation constitute the most realistic behavioural assumption.

Some production processes (for example, paper and electricity) produce both good (or desirable) outputs and bad or undesirable outputs (pollutants). In these cases environmental gains or losses should be included in efficiency measurement. Moreover the disposal of these bad outputs is generally costly because of environmental regulation: limits on the emission of pollutants may constrain or reduce production of desirable outputs. Such regulation implies that bad outputs should be considered as non-freely disposable.

We take into account both managerial objectives and environmental constraints in analysing the productivity of electrical power generation. We measure the ability of one power plant to reduce inputs and undesirable outputs while simultaneously increasing desirable outputs. Following Fare et al. $(1985,1989)$ we measure the performance of power generating units through what they called the enhanced hyperbolic productive efficiency measure.

Using standard notation, we assume that there are $I$ producers who transform a set of inputs $x \in \mathrm{R}_{+}^{\mathrm{n}}$ into outputs $y \in \mathrm{R}_{+}^{\mathrm{m}}$. Let $y=\left(y_{g}, y_{b}\right)$ where $y_{g} \in \mathrm{R}_{+}^{1}$ denotes the subvector of $l$ good outputs and $y_{b} \in \mathrm{R}_{+}^{q}$ the subvector of $q$ bads. Let $\mathrm{X}(n \times I)$ be the matrix of observed inputs, and $\mathrm{M}=\left(\mathrm{M}^{\mathrm{g}}, \mathrm{M}^{\mathrm{b}}\right)$ the output matrix, where $\mathrm{M}^{\mathrm{g}}(l \times I)$ and $\mathrm{M}^{\mathrm{b}}(q \times I)$ denote the submatrices of all desirable outputs and all undesirable outputs respectively. The technology of production can be represented by the Graph, which is the set of all feasible input-output vectors. The piecewise linear representation of the Graph is defined as 


$$
G=\left\{\left(x, y_{g}, y_{b}\right): y_{g} \leq z M^{g}, y_{b}=\mu z M^{b}, z N \leq x, \mu \in[0,1], z \in \mathfrak{R}_{+}^{I}\right\}
$$

where $\mathrm{z}$ is a vector of intensity variables used as weights to construct the piecewise linear frontier of the technology. Inequalities indicate free (or strong) disposability of desirable outputs and inputs, whereas equality indicates weak disposability of undesirable outputs, $\mu$ is a scaling factor required to satisfy weak disposability under variable returns to scale. $G$ characterises the production technology relative to which efficiency is calculated. Thus, the hyperbolic productive efficiency measure is defined as

$$
H=\min \left\{\lambda:\left(\lambda x, \lambda^{-1} y_{g}, \lambda y_{b}\right) \in G\right\}
$$

$H$ provides the equiproportionate expansion of good outputs and contraction of inputs and bad outputs, and is computed as the solution to the mathematical programming problem provided in Appendix 1.That is, (in)efficiency is measured by the distance of each observation from the best-practice frontier constructed by enveloping the data with piecewise linear facets. For comprehensive surveys on both methodological aspects and applications of this approach, see Charnes et al (1994) Lovell (1994) and Färe et al (1994a).

As we explain in the next section, we have a panel with $I$ power plants and $\mathrm{t}=1, \ldots, T$ years, so that we extend our analysis to assess productivity changes across time. We use the Malmquist index approach (Malmquist, 1953) to calculate the total factor productivity change. The utilisation of this approach offers significant advantages over the usual measures of $\mathrm{TFP}^{7}$ in the electricity industry. Firstly, it does not require the definition of a specific form of an underlying production function that characterises the existent technology. Secondly, no pre-specified optimising behaviour by the economic unit, such as cost minimisation or profit maximisation, is assumed. Thirdly, the computation of the Malmquist productivity index does not require price or cost data. Such features are especially valuable in a regulated environment like the electricity industry, characterised by informational asymmetries, price distortions and economies of scale. Additionally, a very attractive characteristic of the Malmquist index is that it is decomposable, permitting the identification of the major sources of any productivity change. Färe et al (1998) provide a recent survey on the main theoretical and practical issues of the Malmquist Productivity Index.

Therefore, the previous hyperbolic productive efficiency measures are used to compute the Graphyperbolic Malmquist Productivity Index proposed by Lovell and Zofío, 1997. Unlike other Malmquist index specifications the Graphyperbolic is neither input- nor output-based (see Färe et al (1994b), Grifell and Lovell (1995, 1997), Bjurek (1996) and Ray and Desli (1997) for alternative definitions and decompositions). The Graphyperbolic Malmquist productivity index relative to period $t$ technology is defined as

\footnotetext{
${ }^{7}$ The Tornqvist Index, as the discrete approximation of the general Solow's (1957) model, is probably the most popular TFP index.
} 


$$
M^{t}\left(x^{t}, y^{t}, x^{t+1}, y^{t+1}\right)=\left[\frac{H_{c}^{t}\left(x^{t+1}, y^{t+1}\right)}{H_{c}^{t}\left(x^{t}, y^{t}\right)}\right]^{2}
$$

where $x^{t}, y^{t}, x^{t+1}, y^{t+1}$ are input and output vectors at times $t$ and $t+1$ respectively. $H_{c}^{t}(y, x)$ is the hyperbolic distance function, where the subscript $c$ indicates that the distance function is computed with reference to the conical technology (i.e. the constant returns to scale technology cone). That is, $M^{t}$ provides a measure of productivity change by comparing $\left(x^{t+1}, y^{t+1}\right)$ to $\left(x^{t}, y^{t}\right)$ using technology prevailing in period $t$ as a reference. An index greater than, equal to, or less than unity indicates that productivity has increased, remained unchanged or declined respectively.

A period $t$ based Graphyperbolic Malmquist productivity index can be multiplicatively decomposed into three elements:

$$
\begin{aligned}
M^{t}\left(x^{t}, y^{t}, x^{t+1}, y^{t+1}\right)= & {\left[\frac{H^{t+1}\left(x^{t+1}, y^{t+1}\right)}{H^{t}\left(x^{t}, y^{t}\right)}\right]^{2} \cdot\left[\frac{H^{t}\left(x^{t+1}, y^{t+1}\right)}{H^{t+1}\left(x^{t+1}, y^{t+1}\right)}\right]^{2} . } \\
& {\left[\frac{H_{c}^{t}\left(x^{t+1}, y^{t+1}\right) / H^{t}\left(x^{t+1}, y^{t+1}\right)}{H_{c}^{t}\left(x^{t}, y^{t}\right) / H^{t}\left(x^{t}, y^{t}\right)}\right]^{2} }
\end{aligned}
$$

The first component measures the magnitude of the change in technical efficiency between period $t$ and $t+1$, i.e. it represents the catching-up effect of the relative movement of each observation towards its own frontier. The component within the second square brackets quantifies the magnitude of technical change or shifts in the production frontier, measured by the change in the relative distance between the frontiers in $t$ and $t+1$. The third term is a scale index which measures the contribution of scale economies to productivity change. The numerator provides an index of the scale efficiency of $\left(x^{t+1}, y^{t+1}\right)$ and the denominator provides a scale index of $\left(x^{t}, y^{t}\right)$, both being relative to period $t$ technology, i.e. it measures the distance of each observation from the technically optimal scale prevailing in period $t$. A value greater (less) than one indicates that a change in the scale of production has lead the unit closer to (away from) the technically optimal scale and in consequence, contributes positively (negatively) to the productivity change. In order to avoid the arbitrary selection of either $t$ or $t+1$ as the reference period, we adopt the usual practice of taking the geometric mean of both $t$ and $t+1$ based Malmquist indices (Färe et al, 1989, 1994a).

Finally we calculate a sequential frontier by constructing the reference production set for year $t$ with the observations at $t$ and all observations up to that year (Tulkens and Vanden Eeckaut, 1995). This approach implies that knowledge does not get lost and past progress is accounted for in the determination of the contemporaneous frontier. Technical regress is not possible with this specification, i.e. only outwards frontier shifts are feasible. 


\section{Data and results}

Generation of electrical power requires three basic inputs: capital, labour and fuel. Capital is measured in MW of capacity, labour as the average number of employees at each plant, and fuel in millions of therms. Output is the annual net power produced by each generating unit, measured in megawatt hours (MWh). Productivity in electricity generation has been traditionally calculated using these variables (Seitz, 1971, Färe et al, 1985, Pollitt, 1995, Coelli et al 1998, among others), and assuming that the plants' objective is to minimise inputs for a given level of output. We report the results of such a conventional analysis of our data in the next section.

However, this traditional approach to the measurement of productive efficiency constitutes a limited framework to evaluate differences in the performance across time and firms in the power generating sector. We adopt a different benchmark model from the traditional approach and include four additional outputs. Firstly, we introduce the declared availability as a second desirable output, measured by the megawatt hours the plant declares available (ready to be called-up). The producers could influence the hours for which plant was declared available, for which they received some revenue to provide an incentive for optimising the management of installed capacity ${ }^{8}$. Secondly, we include three pollutants as undesirable outputs: sulphur dioxide $\left(\mathrm{SO}_{2}\right)$, nitrogen oxide $\left(\mathrm{NO}_{\mathrm{x}}\right)$ and particulates, each measured in tons. The emission of pollutants is constrained by environmental protection restrictions imposed by Spanish law and European directives. We assume that bad outputs are subject to environmental regulation, that is that they are weakly disposable. Installed capacity does not vary for each plant from one year to another, and so we have treated the capacity input as fixed in our initial analysis. This set of assumptions constitutes our reference model (1).

All variables are measured in physical units, as in the purest microeconomic definition of technical efficiency. Since this is an intertemporal analysis, it presents the additional advantage of avoiding different monetary valuations across time. Our purpose is not only the assessment of the relative performance in one period but the productivity change over a period of years. We analyse data from thirty-three generating units, accounting for the entire coal-fired generation in Spain during the period under consideration. Nineteen of them were privately owned and fourteen were under public control. Table 2 gives some characteristics of each group. All data were supplied by the National Electricity Regulatory Commission (CNSE) and Red Eléctrica de España (REE), with the exception of the number of employees, which was extracted from industry sources.

\section{[Table 2 about here]}

One important issue related to differences in the size of the plants is the potential significance of scale economies. Most of the previous engineering and econometric studies estimate that scale economies at the unit level exist up to about 300-400 MW in the case of a base-load coal-powered generator unit (Joskow and Schmalensee,

\footnotetext{
${ }^{8}$ The availability of the existing equipment increased by $12 \%$ between 1984 and 1998 . This would be equivalent to the construction of a 1,250 MW new plant.
} 
1983). We consider as output not only the energy generated but also declared plant availability. As Joskow and Schmalensee also remark, larger units face higher operating and maintenance problems and tend to exhibit lower availability. Given the range of sizes included in this study (see Table 2) we construct a production frontier allowing variable returns to scale.

In order to analyse the evolution of the relative performance between private and public generators over time, we calculate the efficiency measures using the whole sample as the reference production set $^{9}$ (i.e. 462 observations). This gives us a picture of the extent to which less productive units moved closer to the best practice frontier defined by the most efficient generators throughout the whole observation period. If we assume that knowledge accumulates over time, this frontier can be interpreted as the technology feasible during the last year of each period.

Additionally, we construct the average plant for each sector and year and include these artificial plants as additional observations ( 28 units). The purpose is to measure the technical efficiency of both the private and the public sectors. As Førsund and Hjalmarsson (1979) point out, this constitutes an alternative and more satisfactory measure of structural efficiency than the conventional approach suggested by Farrell (1957) of the weighted average (by output) of the efficiency scores of the individual units. There is also the complication when considering more than one output, as we do, of weighting scores in a somewhat arbitrary manner, complicating the interpretation in sectoral terms.

The Spanish electricity industry operated under the MLE as an integrated system with respect to key decision-making, both long term and short term. For example, each unit needs to be out of service occasionally to carry out major checking, repair and maintenance works, affecting the level of availability and power generated. Timetabling of these planned outages was co-ordinated so that they were scheduled in alternate years to avoid a large number of idle plants during any one period. This central co-ordination should be taken into account in interpreting individual efficiency scores for single years.

Table 3 and figure 1 show results for the average private and public generator in model 1, and the (unweighted arithmetic) annual average of the individual scores. Although the magnitudes do not generally coincide (the average of the individual scores is consistently higher) the average firm appears to be representative for generators within that sector, and the patterns are similar. Individual efficiency scores are used in the statistical tests of our hypotheses. The efficiency scores for each plant are given in appendix 3 .

\section{[Table 3 and Figure 1 about here]}

Figure 2 plots the evolution of the intertemporal structural efficiency scores for the average generator in both public and private sectors. We should recall that we are gauging the position of each of these representative firms relative to a stable reference (intertemporal) frontier.

\footnotetext{
${ }^{9}$ We compute what Tulkens and Vanden Eeckaut (1995) call an intertemporal frontier.
} 


\section{[Figure 2 about here]}

Public sector generators are on average more efficient before introduction of the price cap, but the private sector 'catches up' and indeed overtakes the public sector under incentive regulation. Public sector efficiency increases slightly towards the end of the period, immediately before privatisation. We see from table 3 that the average private firm had an efficiency score of 0.953 in 1997, indicating that it could have simultaneously increased good outputs and reduced bad outputs and variable inputs at a rate of $4.7 \%$. The score of 0.849 in 1984 implies a potential productivity improvement of $15.1 \%$. Public generators achieved a score of 0.921 in 1984 and 0.946 in 1997 . The gap between the public and the private sector was reduced from $7.2 \%$ in 1984 to only $0.7 \%$ in 1997 , and reversed in many of the years during the period of the price cap.

In order to identify the annual TFP change, we compute the Graphyperbolic Malmquist productivity index and its component parts as explained in the previous section. The technology for computing the distance functions is constructed as a sequential frontier, described above. The results are shown cumulatively for each sector from a base of 1 in 1984 in Table 4 and Figure 3.

\section{[Table 4 and Figure 3 about here]}

The cumulative index (figure 3a) illustrates the faster increase in productivity amongst private companies in the early years of the price cap, and a fairly similar pattern in the two groups thereafter. However the composition of the increased productivity was somewhat different between the two sectors. Most of the difference in the growth of productivity is accounted for by a large increase in the efficiency index in the private sector around the time that the price cap was introduced, with no improvement (and some falling back) in this measure during the price cap (figure $3 b$ ). This shows that the average efficiency of the private sector increased through improvement by the least efficient plants, relative to the boundary defined by the most efficient. Improved performance of the most efficient firms, shown by the technological change index, was comparatively modest, though somewhat higher in the private than the public sector, especially during the early years of the period (figure 3c). The scale index was rather erratic, with very little difference between the sectors (figure 3d).

To explore the catching up process further we analysed the performance of individual companies within the private sector; table 5 and figure 4 show how much the average efficiency of the companies has converged to the most efficient level since 1984. There were a number of mergers and take-overs during this period, but these do not seem to have played a major part. It seems that private sector efficiency did increase around the time of introducing incentive regulation, by raising the performance of the more inefficient plants and firms; we would expect the introduction of standardised remuneration to have a particularly strong impact on inefficient firms, because of the potential losses which they would otherwise have sustained.

[Table 5 and Figure 4 about here] 
To test our hypotheses on the effects of different types of regulation, including anticipation of privatisation, we used a series of non-parametric tests on our reference model. We divided the sample into three periods: period 1, before the introduction of price cap (1984-1987); period 2, during the price cap until (possible) anticipation of privatisation (1988 to 1994 inclusive); and period 3, the three years immediately before privatisation, 1995-97. To test the hypothesis that public firms are more efficient under cost of service regulation, we used a Mann-Whitney test and a test for the difference in the median of populations for the two sectors in period 1. Both tests rejected the null hypothesis that the populations were the same at a $1 \%$ significance level. We used these two tests and a Wilcoxon test to test for changes in behaviour between period 1 and period 2 (pre and post price cap) in both the private and the public sectors. All three tests rejected the null hypothesis of no change in the private sector at $1 \%$ significance, but provided insufficient evidence for rejecting the null hypothesis in the public sector. We therefore conclude that the price cap increased efficiency in the private sector, but not significantly so in the public sector. Using similar tests we were unable to reject the null hypothesis of equal efficiency in each sector during the price cap (period 2), and that efficiency improved in the public sector immediately prior to privatisation. The statistical tests are reported in appendix 2 .

\section{Variations of the model and comparison with conventional analysis}

We consider two variants of our reference model, described in the previous section. In the first (model 2) we allow capital to vary so that we can assess long run productive efficiency compared with short run efficiency in our reference model. The efficiency scores of the average firms in each sector in Model 2 are shown in figure 5. While this shows a similar pattern to figure 3, the efficiency of the two sectors is much closer during the price cap régime if capital input is allowed to vary. Productivity in the public sector is relatively lower when capital is treated as a fixed input than when capital is allowed to vary; this can be interpreted as the public sector choosing a more efficient level of capital (long run), but the private sector using capital more efficiently in the short-run.

\section{[Figure 5 about here]}

The effectiveness of environmental regulation was addressed by comparing our basic model (with weak disposability of the three pollutants) with a model which differed only in making these bad outputs strongly disposable (model 3). The difference between the two sets of results gives an indication of whether the regulation was binding, and if so its effects on efficiency in terms of lost output (figure 6). Where the graph is zero, regulation is not binding and has had no effect on efficiency as measured by other inputs and outputs. We see that regulation has on average reduced efficiency by $1.4 \%$ in the private sector, and about $1 \%$ in the public sector; this potential increase of good outputs and reduction in inputs measures the 'cost' of imposing environmental regulation. The public sector produces higher levels of pollutants per unit of electricity generated, so it appears that the constraints were laxer for public sector producers, no doubt partly reflecting the government's commitment to continuing production from indigenous lignite (dirty) coal fields. In general, environmental regulation has been binding, and this justifies our choice of weak disposability of bad outputs in our reference model. 


\section{[Figure 6 about here]}

Finally we compare our preferred model with the conventional model (model 4, figure 7). In this model public and private plants appear equally efficient under price cap regulation, in contrast to the slightly (but insignficantly) higher private efficiency shown in model 1. Higher relative efficiency in the private sector in the reference model is partly the effect of short-run efficiency (see comparison of models 1 and 3) and partly because the public plants emitted more sulphur dioxide and particulates per unit of power generated (though slightly less nitrous oxide). The conventional model is unable to identify these effects, both of which are included in model 1.

\section{[Table 5 and Figure 7 about here]}

\section{Conclusions}

Public coal powered generation plants were more efficient than those in the private sector under cost of service regulation. Public sector managers did indeed seem to take the social cost of subsidies into account, more than at least some of their private sector counterparts. In particular the wide divergence of performance between different private companies suggests that some companies and plant managers were little motivated by concerns of efficiency; however it should be noted that some of the private plants were amongst the most efficient throughout the period, including these early years (the most efficient plants in each year included representatives from both private and public firms, see appendix 3).

Price cap regulation produced a dramatic change, raising the performance of the least efficient private sector plants and so significantly improving average private sector performance. The fact that not only the less efficient plants but also the less efficient companies dramatically improved performance, suggests that this was indeed a result of the incentive effect of the price cap on the less efficient private firms, who succeeded in transmitting these incentives to plant managers. The timing of the private sector improvements is particularly striking and seems to be directly related to the introduction of the price cap (figures $3 b$ and 4), rather than any of the mergers which occurred somewhat later in the period. The price cap seems to have been a highly effective incentive mechanism for the private sector in its short run operating decisions, and to have achieved its objective of stimulating efficiency.

Less efficient public sector plants also showed some catching up with their most efficient exemplars over the period, but the effect was much less dramatic, and overall efficiency in the public sector did not show a statistically significant improvement after the price cap was introduced. Similarly, although there is some evidence that the less efficient public sector plants were moving (erratically) closer to the efficient frontier in anticipation of privatisation after 1994, there was not a statistically significant growth in overall efficiency.

Environmental regulation during the period was binding, and had a 'cost' of about $1 \%$ of output in the public sector and $1.4 \%$ in the private sector. When we compared long run (variable capital input) with our reference model short-run specification we found 
that the public plants became more efficient relative to private plants throughout most of the period (model 2, figure 5). Thus while private plants were on average more efficient than the private sector with fixed capital (short-run), the public plants may have (chosen) a more appropriate level of capital and be relatively more efficient in the long-run. Since all the plants in our sample were commissioned before 1988 this does not directly support Laffont and Crampes' concerns about the undesirable incentive effects of the MLE on investment, but does suggest some more general concerns about investment choices ${ }^{10}$. In particular there may be some important policy implications for future investment decisions, and for how any stranded capital is treated in the new (post 1998) competitive market.

We raise some methodological issues about the most appropriate measures of input and output in a centrally despatched system where generators' order of despatch is determined exogenously, and suggest an alternative to the standard use of power generation as a single output, including the declared plant availability, since this partially determined the Spanish firms' revenues. Three pollutants are also included to reflect recent changes in environmental requirements, and we looked both at fixed and variable capital input to distinguish short term and long term efficiency.

Our results challenge some of the conventional wisdom on productive efficiency in the public and private sectors under both cost of service and incentive regulation. The private sector improvement during price cap regulation, $1.9 \%$ a year, compares with an annual increase of 5.6\% for all electricity plants in the UK in 1990-95, where incentive regulation and competition were accompanied by privatisation (Utilities Journal, 1998). However the Spanish private sector increases were significantly higher than the $0.47 \%$ annual increase in Australian coal-fired generation during the period 1981-1991 (Coelli et al 1998).

The Spanish experience enables us to distinguish the effects of regulatory régimes on each sector. We can compare productivity changes within both public and private companies while they were undergoing the same regulatory reform but not subject to any changes of ownership or market structure. Our results support our hypotheses that public firms are more efficient under cost of service regulation and that incentive regulation will increase efficiency in the private sector. These results have important implications for policy design in this and similar sectors in many countries where ownership, market structure and regulatory design are currently being fundamentally reformed. In particular, regulatory mechanisms should be designed to fit the ownership structure to which they are applied: while incentive regulation may increase the productivity of privately owned firms, cost of service regulation may be more appropriate for plants within the public sector.

\footnotetext{
${ }^{10}$ Our analysis does not include the distribution part of the industry, which was also part of Laffont and Crampes' concern.
} 


\section{Appendix 1}

We assume that there are $i=1, \ldots, I_{t}$ observations and $t=1, \ldots, T$ periods of time. Each firm uses $x_{v}^{i t}=\left(x_{1}^{i t}, \ldots, x_{V}^{i t}\right)$ variable inputs and $x_{f}^{i t}=\left(x_{1}^{i t}, \ldots, x_{F}^{i t}\right)$ fixed inputs to produce $y_{g}^{i t}=\left(y_{1}^{i t}, \ldots, y_{L}^{i t}\right)$ good outputs and $y_{b}^{i t}=\left(y_{1}^{i t}, \ldots, y_{Q}^{i t}\right)$. The efficiency measures necessary to calculate the Graphyperbolic Malmquist productivity index can be obtained by solving the following programming problems (notice that the technology is sequentially defined from $s=1$ up until $s=t$ ):

$H^{s}\left(x^{i t}, y^{i t}\right)=\min \lambda$

subject to

$\lambda^{-1} y_{g, l}^{i t} \leq \sum_{i=1}^{I_{t}} \sum_{s=1}^{t} z^{i s} y_{g, l}^{i s} \quad l=1, \ldots, L$

$\lambda y_{b, q}^{i t}=\mu \sum_{i=1}^{I_{t}} \sum_{s=1}^{t} z^{i s} y_{b, q}^{i s} \quad q=1, \ldots, Q$

$\sum_{i=1}^{I_{t}} \sum_{s=1}^{t} z^{i s} x_{v}^{i s} \leq \lambda x_{v}^{i t} \quad v=1, \ldots, V$

$\sum_{i=1}^{I_{t}} \sum_{s=1}^{t} z^{i s} x_{f}^{i s} \leq x_{f}^{i t} \quad f=1, \ldots, F$

$\sum_{i=1}^{I_{t}} \sum_{s=1}^{t} z^{i s}=1$

$z^{i s} \geq 0 \quad i=1, \ldots, I_{t}, s=1, \ldots, t$

$0 \leq \mu \leq 1$
$H^{s}\left(x^{i t+1}, y^{i t+1}\right)=\min \lambda$

subject to

$\lambda^{-1} y_{g, l}^{i t+1} \leq \sum_{i=1}^{I_{t}} \sum_{s=1}^{t} z^{i s} y_{g, l}^{i s} \quad l=1, \ldots, L$

$\lambda y_{b, q}^{i t+1}=\mu \sum_{i=1}^{I_{t}} \sum_{s=1}^{t} z^{i s} y_{b, q}^{i s} \quad q=1, \ldots, Q$

$\sum_{i=1}^{I_{t}} \sum_{s=1}^{t} z^{i s} x_{v}^{i s} \leq \lambda x_{v}^{i t+1} \quad v=1, \ldots, V$

$\sum_{i=1}^{I_{t}} \sum_{s=1}^{t} z^{i s} x_{f}^{i s} \leq x_{f}^{i t+1} \quad f=1, \ldots, F$

$\sum_{i=1}^{I_{t}} \sum_{s=1}^{t} z^{i s}=1$

$z^{i s} \geq 0$

$i=1, \ldots, I_{t}, s=1, \ldots, t$

$0 \leq \mu \leq 1$

Efficiency measures referred to the conical technology are computed by deleting the constraint $\sum_{i=1}^{I_{t}} \sum_{s=1}^{t} z^{i s}=1$

Strong disposability of bad ouputs is computed by replacing the equality in the second restriction by inequality. 


\section{Appendix 2}

Summary of statistical tests for the alternative hypotheses

\begin{tabular}{lccc}
\hline & Mann-Whitney & Median Scores & Wilcoxon \\
\hline & $\begin{array}{c}\mathrm{Z} \\
(\text { Prob }>\mathrm{Z})\end{array}$ & $\begin{array}{c}\chi^{2} \\
\left(\text { Prob }>\chi^{2}\right)\end{array}$ & $\begin{array}{c}\mathrm{Z} \\
(\text { Prob }>\mathrm{Z})\end{array}$ \\
Hypothesis 1 & -3.004 & 11.455 & - \\
& $(0.003)$ & $(0.001)$ & \\
Hypothesis 2a & -3.868 & 10.351 & -2.938 \\
& $(0.001)$ & $(0.001)$ & $(0.003)$ \\
Hypothesis 2b & -0.292 & 0.845 & 0.847 \\
Hypothesis 3 & $(0.770)$ & $(0.358)$ & $(0.397)$ \\
& -1.148 & 0.044 & -- \\
Hypothesis 4 & $(0.251)$ & $(0.833)$ & -0.105 \\
& -0.412 & 2.352 & $(0.917)$ \\
\hline
\end{tabular}

Hypothesis 1: public versus private efficiency in period 1 (1984-1987) Hypothesis 2a: private efficiency in period 2 greater than that in period 1 Hypothesis 2b: public efficiency in period 2 greater than that in period 1 Hypothesis 3: public versus private efficiency in period 2.

Hypothesis 4: public efficiency in period 2 and 3 (to test anticipation of privatisation)

A value of less than 0.05 in the bracket below each test statistic indicates rejection at the $5 \%$ level of the null hypothesis of no difference in efficiency. 
Appendix 3: Efficiency Scores for each plant: Model 1

\begin{tabular}{|c|c|c|c|c|c|c|c|c|c|c|c|c|c|c|}
\hline & 1984 & 1985 & 1986 & 1987 & 1988 & 1989 & 1990 & 1991 & 1992 & 1993 & 1994 & 1995 & 1996 & 1997 \\
\hline \multicolumn{15}{|c|}{ PUBLIC } \\
\hline $\begin{array}{l}\text { unit } 1 \\
\text { unit } 2\end{array}$ & 1.0000 & 1.0000 & 1.0000 & 1.0000 & 1.0000 & 0.9871 & 1.0000 & 1.0000 & 1.0000 & 1.0000 & 1.0000 & 1.0000 & 1.0000 & $\begin{array}{l}1.0000 \\
1.0000\end{array}$ \\
\hline $\begin{array}{l}\text { unit } 2 \\
\text { unit } 3\end{array}$ & * & $* *$ & 1.0000 & 0.9948 & 1.0000 & 1.0000 & 1.0000 & 1.0000 & 1.0000 & 1.0000 & 1.0000 & 1.0000 & 1.0000 & 1.0000 \\
\hline unit 3 & 0.8899 & 0.9907 & 0.9535 & 0.9381 & 0.9766 & 0.9729 & 0.9692 & 0.9718 & 0.9556 & 0.9585 & 0.9801 & 0.9906 & 0.9755 & 0.9920 \\
\hline unit 4 & 1.0000 & 0.9550 & 0.9478 & 0.9205 & 0.9775 & 0.9761 & 0.9781 & 0.9833 & 0.9705 & 0.9836 & 0.9770 & 0.9939 & 1.0000 & 1.0000 \\
\hline unit 5 & $*$ & 0.9727 & 0.9462 & 0.9477 & 0.9816 & 0.9861 & 0.9856 & 1.0000 & 0.9766 & 1.0000 & 0.9847 & 0.9864 & 0.9993 & 1.0000 \\
\hline unit 6 & $*$ & 0.9814 & 0.9919 & 0.9926 & 0.9820 & 1.0000 & 0.9883 & 1.0000 & 1.0000 & 1.0000 & 1.0000 & 1.0000 & 1.0000 & 1.0000 \\
\hline unit 7 & 0.8577 & 0.8548 & 0.9852 & 0.8663 & 0.9971 & 0.9724 & 0.9809 & 0.9656 & 0.9845 & 0.9559 & 0.9819 & 0.9942 & 1.0000 & 1.0000 \\
\hline unit 8 & 0.9213 & 0.8956 & 1.0000 & 0.9623 & 0.9611 & 1.0000 & 1.0000 & 1.0000 & 0.9393 & 0.9808 & 1.0000 & 0.8735 & 0.9659 & 0.9671 \\
\hline unit 9 & 1.0000 & 1.0000 & 1.0000 & 0.9609 & 0.9687 & 0.9858 & 1.0000 & 0.9768 & 0.9516 & 0.9525 & 1.0000 & 0.9140 & 0.8811 & 0.9606 \\
\hline unit 10 & 1.0000 & 1.0000 & 1.0000 & 1.0000 & 0.9788 & 0.9803 & 1.0000 & 1.0000 & 0.9671 & 0.9606 & 1.0000 & 0.9979 & 0.9682 & 0.9945 \\
\hline unit 11 & 0.9954 & 1.0000 & 0.9947 & 0.9786 & 0.9663 & 0.9834 & 1.0000 & 0.9814 & 0.9311 & 0.9472 & 1.0000 & 0.9777 & 0.9975 & 0.8822 \\
\hline unit 12 & 0.9885 & 1.0000 & 1.0000 & 0.9926 & 1.0000 & 0.9606 & 1.0000 & 0.9718 & 1.0000 & 0.9900 & 0.9338 & 0.9927 & 1.0000 & 1.0000 \\
\hline unit 13 & 1.0000 & 1.0000 & 0.9816 & 0.9989 & 0.9561 & 0.9935 & 1.0000 & 0.9722 & 1.0000 & 0.9305 & 1.0000 & 0.9962 & 0.9983 & 0.9359 \\
\hline unit 14 & 0.9957 & 1.0000 & 1.0000 & 1.0000 & 0.9608 & 1.0000 & 0.9954 & 1.0000 & 1.0000 & 1.0000 & 0.9942 & 0.9503 & 1.0000 & 0.9959 \\
\hline \multicolumn{15}{|c|}{ PRIVATE } \\
\hline unit 1 & 1.0000 & 1.0000 & 1.0000 & 1.0000 & 0.9810 & 1.0000 & 1.0000 & 1.0000 & 1.0000 & 1.0000 & 0.9951 & 0.9891 & 0.9847 & 0.9524 \\
\hline unit 2 & * & 1.0000 & 1.0000 & 1.0000 & 1.0000 & 1.0000 & 1.0000 & 1.0000 & 0.9962 & 1.0000 & 0.9928 & 1.0000 & 1.0000 & 1.0000 \\
\hline unit 3 & 0.9219 & 0.9219 & 0.9205 & 0.9676 & 1.0000 & 0.9899 & 1.0000 & 0.9985 & 0.9981 & 0.9891 & 0.9836 & 1.0000 & 0.9955 & 1.0000 \\
\hline unit 4 & $*$ & 0.9649 & 0.9798 & 0.9771 & 0.9734 & 1.0000 & 1.0000 & 0.9856 & 1.0000 & 0.9906 & 1.0000 & 0.9933 & 0.9981 & 1.0000 \\
\hline unit 5 & 1.0000 & 1.0000 & 0.9908 & 1.0000 & 1.0000 & 0.9639 & 1.0000 & 0.9836 & 1.0000 & 0.9927 & 0.9887 & 0.9518 & 1.0000 & 1.0000 \\
\hline unit 6 & 1.0000 & 0.9675 & 0.9806 & 1.0000 & 1.0000 & 0.9748 & 0.9747 & 0.9764 & 0.9521 & 0.9679 & 1.0000 & 1.0000 & 1.0000 & 1.0000 \\
\hline unit 7 & $*$ & 0.8933 & 0.9024 & 0.9110 & 0.9554 & 0.9657 & 0.9613 & 0.9760 & 0.9770 & 0.9697 & 0.9766 & 0.9806 & 0.9883 & 0.9794 \\
\hline unit 8 & 1.0000 & 1.0000 & 0.9813 & 0.9036 & 1.0000 & 1.0000 & 0.9519 & 0.9614 & 0.9868 & 1.0000 & 1.0000 & 0.9823 & 1.0000 & 0.9570 \\
\hline unit 9 & 1.0000 & 0.8217 & 0.8933 & 0.8691 & 0.9570 & 0.9567 & 0.9662 & 0.9366 & 0.9454 & 0.9367 & 0.9583 & 0.9645 & 0.9731 & 0.9501 \\
\hline unit 10 & 0.9461 & 1.0000 & 0.9652 & 0.9832 & 1.0000 & 1.0000 & 0.9992 & 0.9657 & 1.0000 & 1.0000 & 0.9426 & 1.0000 & 1.0000 & 1.0000 \\
\hline unit 11 & 0.8516 & 0.9668 & 0.9774 & 0.9771 & 0.9996 & 0.9904 & 1.0000 & 1.0000 & 1.0000 & 0.9937 & 1.0000 & 1.0000 & 1.0000 & 1.0000 \\
\hline unit 12 & * & 0.9176 & 0.9772 & 0.9474 & 0.9715 & 0.9595 & 0.9945 & 0.9862 & 0.9844 & 0.9976 & 0.9958 & 0.9982 & 1.0000 & 0.9920 \\
\hline unit 13 & 1.0000 & 0.9922 & 0.9610 & 0.9581 & 1.0000 & 0.9767 & 0.9444 & 0.9720 & 0.9854 & 0.9702 & 0.9697 & 0.9770 & 1.0000 & 1.0000 \\
\hline unit 14 & 0.8338 & 0.8271 & 0.7847 & 0.8238 & 0.9351 & 0.9999 & 0.9203 & 0.9559 & 0.9313 & 0.9420 & 0.9615 & 0.9520 & 0.9639 & 0.9890 \\
\hline unit 15 & 0.9150 & 0.8927 & 0.8979 & 0.9099 & 1.0000 & 0.9804 & 0.9113 & 0.9620 & 0.9633 & 0.9550 & 0.9622 & 0.9966 & 1.0000 & 0.9939 \\
\hline unit 16 & $*$ & 0.8927 & 0.8964 & 0.9226 & 1.0000 & 1.0000 & 1.0000 & 0.9886 & 0.9997 & 0.9816 & 0.9872 & 0.9966 & 1.0000 & 1.0000 \\
\hline unit 17 & 1.0000 & 1.0000 & 0.9963 & 0.9450 & 0.8953 & 0.9062 & 1.0000 & 1.0000 & 1.0000 & 1.0000 & 1.0000 & 0.9462 & 0.9793 & 1.0000 \\
\hline unit 18 & 0.8878 & 0.8690 & 0.8885 & 0.9795 & 0.9858 & 0.9453 & 0.9867 & 0.9535 & 1.0000 & 0.9631 & 0.9885 & 0.9986 & 0.9958 & 0.9558 \\
\hline unit 19 & * & 0.9735 & 0.8617 & 0.9071 & 0.9878 & 0.9620 & 0.9934 & 0.9701 & 0.9757 & 0.9897 & 0.9706 & 0.9925 & 1.0000 & 1.0000 \\
\hline
\end{tabular}

* These plants were commisioned in 1985

** The plant did not operate that year. 


\section{References}

Arocena, P., Kühn, K-U and Regibeau, P. (1998) "Regulatory Reform in the Spanish Electricity Industry: A Missed Opportunity for Competition", Centre for Management under Regulation, Research Paper Series No.98/1.Warwick Business School, University of Warwick.

Bjurek, H. (1996), “The Malmquist Total Factor Productivity Index”, Scandinavian Journal of Economics, 98(2), pp. 303-313.

Caillaud, B., Guesnerie, R., Rey, P. and Tirole, J. (1988) "Government intervention in production and incentives theory: a review of recent criticisms", The Rand Journal of Economics, 98 (2) pp303-313

Charnes, A., Cooper, W. Lewin, A., and Seiford, L. (1994). Data Envelopment Analysis. Theory, Methodology and Applications. Dordrecht .Kluwer Academic Publishers.

Coelli, T., Rao, D. and Battese, G. (1998) An introduction to efficiency and productivity analysis. Dordrecht. Kluwer Academic Publishers.

CSEN (1997). Información básica del Sector Eléctrico. Madrid. Comisión del Sistema Eléctrico Nacional.

de Fraja, G. (1993) "Productive efficiency in public and private firms", Journal of Public Economics, 30, pp 15-30

Färe, R., Grosskopf, S. and Lovell, C.A.K. (1994a). Production Frontiers. Cambridge University Press.

Färe, R., Grosskopf, S. and Roos, P. (1998) "Malmquist productivity indexes: a survey of theory and practice", in Färe, R., Grosskopf, S. and Russell, R. (editors) (1998) Index numbers: essays in honour of Sten Malmquist, Boston: Kluwer Academic Publishers.

Färe, R., Grosskopf, S., Logan, J. and Lovell, C.A.K. (1985). "Measuring Efficiency in Production: With an Application to Electric Utilities" in Dogramaci, A. y Adam, N. (eds), Managerial Issues in Productivity Analysis. Boston: Kluwer-Nijhoff.

Färe, R., Grosskopf, S., Lindgren, B. and Ross, P. (1989) "Productivity Developments in Swedish Hospitals: A Malmquist Output Index Approach", in Charnes, A., Cooper, W. Lewin, A., and Seiford, L. (eds.) (1994), Data Envelopment Analysis. Theory, Methodology and Applications. Boston: Kluwer Academic Publishers.

Färe, R., Grosskopf, S., Norris, M. and Zhang, Z. (1994b) "Productivity Growth, Technical Progress, and Efficiency Change in Industrialized Countries", American Economic Review, 84 (1), págs. 66-83

Farrell, M.J. (1957). "The measurement of Productive Efficiency", Journal of the Royal Statistical Society, Series A, General, 120(3), pp.: 253-282.

Fernández-Ordóñez, M.A. (1996), "La economía y la transparencia. La insoportable oscuridad del sector eléctrico". El País, 11 de noviembre de 1996.

Førsund, F. and Hjalmarsson, L. (1979). "Generalised Farrell measures of efficiency: an application to milk processing in Swedish dairy plants", The Economic Journal, 89, 294-315.

Grifell-Tatjé, E. and Lovell, C.A.K. (1995). “A generalized Malmquist productivity index", Working Paper, Department of Economics, University of Georgia, Athens, GA 30602, USA.

Grifell-Tatjé, E. and Lovell, C.A.K. (1997), "The sources of productivity change in Spanish banking", European Journal of Operational Research 98, 364-380. 
Joskow, T. and Schmalensee, R. (1983). Markets for Power. Cambridge: MA. The MIT Press.

Kahn, E. (1996). "The Electricity Industry in Spain”, Electricity Journal, 9(2), pp 4655.

Laffont, J-J and Crampes, C., Transfers and Incentives in the Spanish Electricity Sector, Revista Española de Economia, 2, "Regulación", 117-140

Laffont, J-J and Tirole, J., 1993, A Theory of Incentives in Procurement and Regulation, Cambridge, MIT press

Liston, C. (1993) "Price-cap vs Rate-of-return regulation" Journal of Regulatory Economics, 5:25-48

Littlechild, S. (1983). Regulation of British Telecommunications Profitability. London. HMSO.

Lovell, C.A.K. (1994) "Linear Programming Approaches to the Measurement and Analysis of Productive Efficiency", Top 2(2), 175-248.

Lovell, C.A.K. and Zofío, J.L.(1997) "Graphyperbolic Efficiency and Productivity Measures", paper presented at the Fifth European Workshop on Efficiency and Productivity Analysis, Copenhagen, Denmark.

Malmquist, S. (1953). "Index Numbers and Indifference Curves." Trabajos de Estadística 4, pp. 209-242.

Newbery, D and Pollitt, M. G. (1997), "The restructuring and privatisation of Britain's CEGB - was it worth it?", Journal of Industrial Economics XLV, 3, pp 269-304

Pollitt, M. G. (1995), Ownership and performance in electric utilities. Oxford. Oxford University Press.

Ray, S. and Desli, E. (1997) "Productivity Growth, Technical Progress, and Efficiency Change in Industrialized Countries: Comment". American Economic Review 87(5), pp 1033-1043.

REE (1997). Explotación del Sistema Eléctrico. Informe 1997.

Seitz, W (1971). "Productive Efficiency in the steam electric generating industry". Journal of Political Economy, 79(4), pp. 878-886

Solow, R. M. (1957). "Technical change and the aggregate production function", Review of Economics and Statistics, 49(3), 312-320.

The Utilities Journal, January 1998.

Tulkens, H. and Vanden Eeckaut, P. (1995) "Non-parametric efficiency, progress and regress measures for panel data: methodological aspects". European Journal of Operational Research, 80 (3), 474-499.

Vickers, J. and Yarrow, G. (1988) Privatization: An Economic Analysis, MIT Press, Cambridge, Massachusetts.

Waddams Price,C. and Weyman-Jones, T. (1996) "Malmquist indices of productivity change in the UK gas industry before and after privatization", Applied Economics, 28, pp 29-39 
Table 1. Capacity and generation by fuel type and average production shares during 1984-1997 (autoproducers not included)

\begin{tabular}{|c|c|c|c|c|}
\hline & \multicolumn{2}{|c|}{ Capacity (MW) } & \multicolumn{2}{|c|}{ Production $(\mathrm{GWH})$} \\
\hline & 1997 & 1984-1997 & 1997 & 1984-1997 \\
\hline Hydro & 16,532 & $37 \%$ & 33,168 & $20 \%$ \\
\hline Coal & 11,224 & $26 \%$ & 62,098 & $42 \%$ \\
\hline Nuclear & 7,581 & $16 \%$ & 55,297 & $35 \%$ \\
\hline Oil + Gas & 8,214 & $21 \%$ & 6,844 & $3 \%$ \\
\hline Total & 43,551 & & 157,407 & \\
\hline
\end{tabular}

Source: Adapted from CSEN (1997) and REE (1997)

Table 2. Plant characteristics by type of ownership (mean values 1984-1997)

\begin{tabular}{lll}
\hline & \multicolumn{1}{c}{ Private } & \multicolumn{1}{c}{ Public } \\
\hline Average capacity (MW) & 307 & 330 \\
Range (MW) & $148-550$ & $141-550$ \\
Average age in 1984 (years) & 8.6 & 7.9 \\
Utilisation & $66.2 \%$ & $80.5 \%$ \\
Availability & $91.6 \%$ & $90.7 \%$ \\
MWh/employee & 9,173 & 9,942 \\
MWh/(Instal.Cap.*Oper.Hours) & 0.861 & 0.834 \\
Therms/MWh & 2,698 & 2,732 \\
Grams of Particulates / MWh & 583 & 638 \\
Grams of SO2 emissions / MWh & 12,788 & 32,012 \\
Grams of NOx emissions/ MWh & 3,928 & 3,283 \\
\hline
\end{tabular}


Table 3: Intertemporal structural efficiency: model 1

\begin{tabular}{ccccc}
\hline & \multicolumn{2}{c}{ Average firm } & \multicolumn{2}{c}{ Average of individual scores } \\
& Public & Private & Public & Private \\
1984 & 0.921 & 0.849 & 0.968 & 0.950 \\
1985 & 0.926 & 0.882 & 0.973 & 0.942 \\
1986 & 0.907 & 0.897 & 0.986 & 0.940 \\
1987 & 0.899 & 0.898 & 0.968 & 0.946 \\
1988 & 0.906 & 0.944 & 0.979 & 0.981 \\
1989 & 0.926 & 0.940 & 0.986 & 0.977 \\
1990 & 0.926 & 0.946 & 0.993 & 0.979 \\
1991 & 0.925 & 0.949 & 0.987 & 0.977 \\
1992 & 0.930 & 0.950 & 0.977 & 0.984 \\
1993 & 0.925 & 0.952 & 0.976 & 0.981 \\
1994 & 0.924 & 0.951 & 0.989 & 0.983 \\
1995 & 0.943 & 0.955 & 0.976 & 0.985 \\
1996 & 0.946 & 0.959 & 0.985 & 0.994 \\
1997 & 0.946 & 0.953 & 0.981 & 0.988 \\
Mean & 0.925 & 0.930 & 0.980 & 0.972 \\
\hline
\end{tabular}


Table 4. Chained Graphyberbolic Malmquist Productivity Index and its components (model 1)

\begin{tabular}{lcccc}
\hline Private sector & $\begin{array}{c}\text { Graphyperbolic } \\
\text { Malmquist }\end{array}$ & $\begin{array}{c}\text { Efficiency } \\
\text { change }\end{array}$ & $\begin{array}{c}\text { Technological } \\
\text { change }\end{array}$ & Scale index \\
& 1 & 1 & & \\
1984 & 1.105 & 0.963 & 1.156 & 0.992 \\
1985 & 1.138 & 0.977 & 1.162 & 1.002 \\
1986 & 1.170 & 1.020 & 1.170 & 0.980 \\
1987 & 1.346 & 1.056 & 1.232 & 1.035 \\
1988 & 1.346 & 1.057 & 1.251 & 1.018 \\
1989 & 1.372 & 1.060 & 1.270 & 1.020 \\
1990 & 1.382 & 1.053 & 1.282 & 1.023 \\
1991 & 1.384 & 1.048 & 1.300 & 1.016 \\
1992 & 1.396 & 1.048 & 1.304 & 1.021 \\
1993 & 1.392 & 1.046 & 1.304 & 1.021 \\
1994 & 1.398 & 1.049 & 1.304 & 1.022 \\
1995 & 1.387 & 1.051 & 1.305 & 1.011 \\
1996 & 1.401 & 1.046 & 1.306 & 1.026 \\
1997 & & &
\end{tabular}

Public sector

Graphyperbolic
Malmquist $\quad \begin{gathered}\text { Efficiency } \\ \text { change }\end{gathered} \quad \begin{gathered}\text { Technological Scale index } \\ \text { change }\end{gathered}$

\begin{tabular}{lcccc}
1984 & 1 & 1 & 1 & 1 \\
1985 & 1.011 & 0.949 & 1.055 & 1.009 \\
1986 & 0.949 & 0.929 & 1.069 & 0.956 \\
1987 & 0.937 & 0.911 & 1.105 & 0.930 \\
1988 & 1.043 & 0.927 & 1.120 & 1.005 \\
1989 & 1.105 & 0.958 & 1.126 & 1.024 \\
1990 & 1.121 & 0.940 & 1.133 & 1.053 \\
1991 & 1.099 & 0.946 & 1.136 & 1.023 \\
1992 & 1.117 & 0.940 & 1.150 & 1.034 \\
1993 & 1.128 & 0.954 & 1.151 & 1.027 \\
1994 & 1.127 & 0.951 & 1.151 & 1.030 \\
1995 & 1.163 & 0.991 & 1.155 & 1.015 \\
1996 & 1.145 & 0.957 & 1.155 & 1.034 \\
1997 & 1.159 & 0.987 & 1.160 & 1.013 \\
\hline
\end{tabular}


Table 5: Efficiency scores of individual firms

\begin{tabular}{lccccccc}
\hline & $\begin{array}{c}\text { ENDESA } \\
\text { public } \\
(14)\end{array}$ & $\begin{array}{c}\text { IBERDROLA } \\
(5)\end{array}$ & $\begin{array}{c}\text { UNIÓN } \\
\text { FENOSA } \\
(6)\end{array}$ & $\begin{array}{c}\text { HIDRO } \\
\text { CANTABRICO }\end{array}$ & $\begin{array}{c}\text { FECSA } \\
(2)\end{array}$ & $\begin{array}{c}\text { SEVILLANA } \\
(2)\end{array}$ & $\begin{array}{c}\text { JOINT- } \\
\text { VENTURES }\end{array}$ \\
\hline $\mathbf{1 9 8 4}$ & 0.9680 & 0.9722 & 0.9087 & 1.0000 & 1.0000 & 0.8338 & 0.8878 \\
$\mathbf{1 9 8 5}$ & 0.9731 & 0.9349 & 0.9320 & 1.0000 & 1.0000 & 0.8960 & 0.9213 \\
$\mathbf{1 9 8 6}$ & 0.9858 & 0.9343 & 0.9391 & 1.0000 & 0.9936 & 0.8823 & 0.8751 \\
$\mathbf{1 9 8 7}$ & 0.9681 & 0.9284 & 0.9513 & 1.0000 & 0.9725 & 0.9005 & 0.9433 \\
$\mathbf{1 9 8 8}$ & 0.9790 & 0.9825 & 0.9952 & 0.9905 & 0.9477 & 0.9543 & 0.9868 \\
$\mathbf{1 9 8 9}$ & 0.9856 & 0.9748 & 0.9867 & 1.0000 & 0.9351 & 1.0000 & 0.9537 \\
$\mathbf{1 9 9 0}$ & 0.9927 & 0.9597 & 0.9842 & 1.0000 & 1.0000 & 0.9602 & 0.9901 \\
$\mathbf{1 9 9 1}$ & 0.9874 & 0.9645 & 0.9835 & 1.0000 & 0.9918 & 0.9708 & 0.9618 \\
$\mathbf{1 9 9 2}$ & 0.9769 & 0.9653 & 0.9909 & 0.9981 & 1.0000 & 0.9657 & 0.9879 \\
$\mathbf{1 9 9 3}$ & 0.9772 & 0.9689 & 0.9862 & 1.0000 & 0.9964 & 0.9663 & 0.9764 \\
$\mathbf{1 9 9 4}$ & 0.9894 & 0.9809 & 0.9786 & 0.9940 & 0.9944 & 0.9808 & 0.9796 \\
$\mathbf{1 9 9 5}$ & 0.9762 & 0.9809 & 0.9986 & 0.9946 & 0.9490 & 0.9727 & 0.9956 \\
$\mathbf{1 9 9 6}$ & 0.9847 & 0.9923 & 0.9993 & 0.9924 & 0.9897 & 0.9810 & 1.0000 \\
$\mathbf{1 9 9 7}$ & 0.9806 & 0.9773 & 0.9977 & 0.9762 & 1.0000 & 0.9945 & 0.9779 \\
\hline
\end{tabular}

Table 6: Intertemporal structural efficiency: conventional model (4)

\begin{tabular}{ccc}
\hline \multicolumn{2}{c}{ Average firm } \\
\hline & Public & Private \\
1984 & 0.869 & 0.715 \\
1985 & 0.834 & 0.746 \\
1986 & 0.811 & 0.756 \\
1987 & 0.815 & 0.761 \\
1988 & 0.775 & 0.818 \\
1989 & 0.838 & 0.838 \\
1990 & 0.836 & 0.846 \\
1991 & 0.853 & 0.847 \\
1992 & 0.867 & 0.861 \\
1993 & 0.868 & 0.858 \\
1994 & 0.861 & 0.858 \\
1995 & 0.897 & 0.866 \\
1996 & 0.853 & 0.83 \\
1997 & 0.892 & 0.857 \\
Mean & 0.848 & 0.818 \\
\hline
\end{tabular}


Figure 1: Intertemporal structural efficiency: comparison of the scores of the 'average firm' with the mean of the individual scores in each sector (model 1).

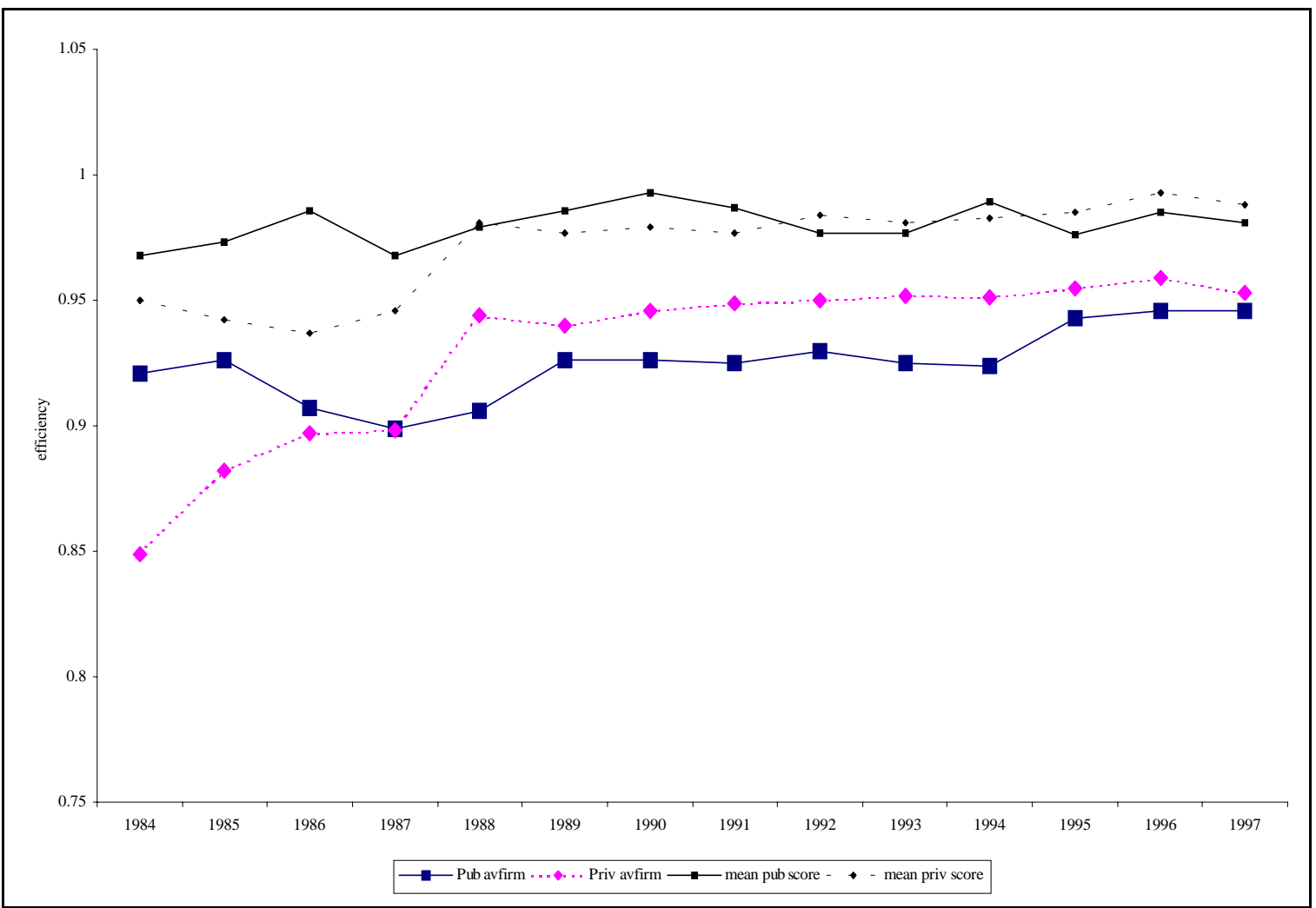

Figure 2. Evolution of structural efficiency in public and private sectors. Model 1

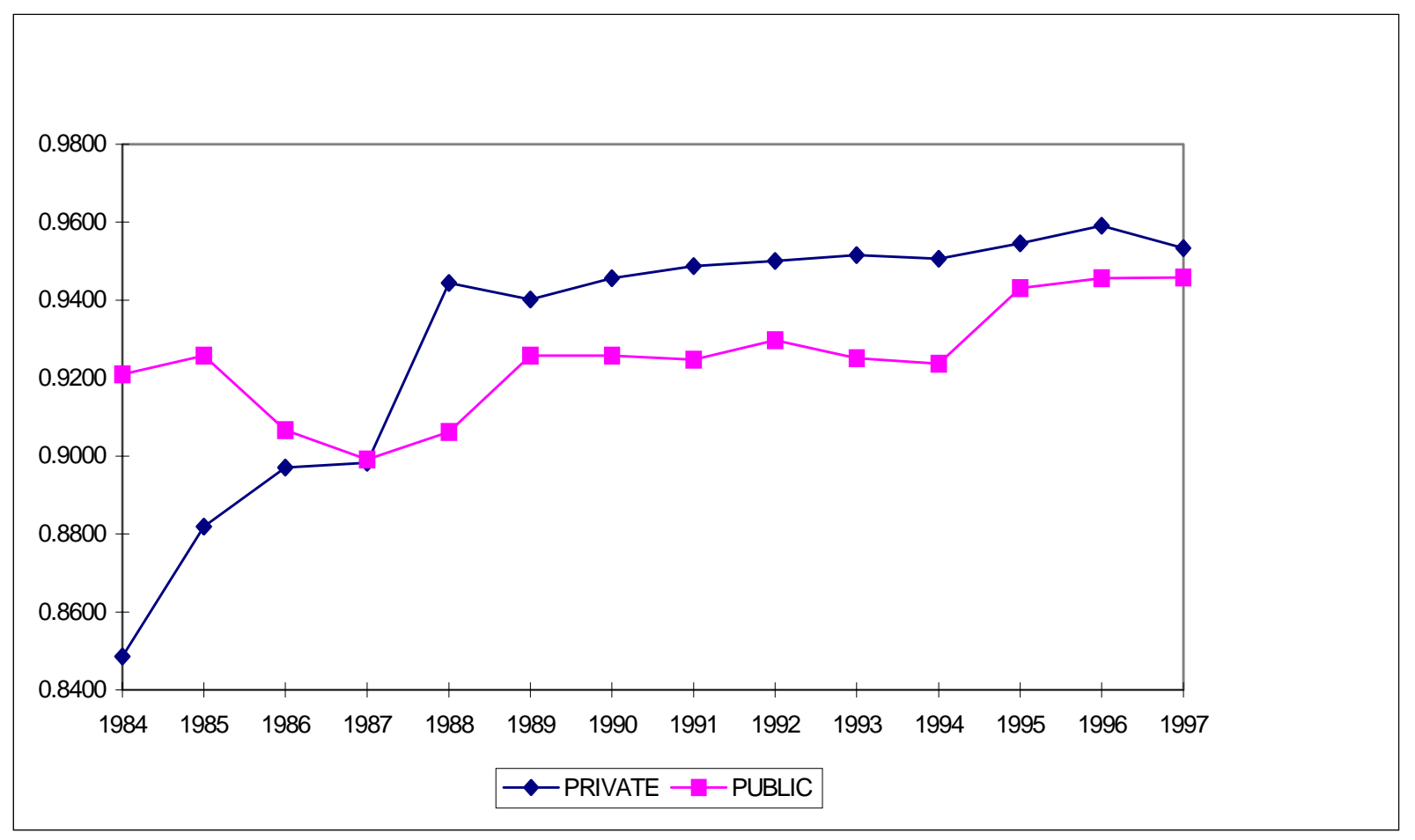


Figure 3a: Chained productivity growth ( graphyperbolic malmquist index) : model 1

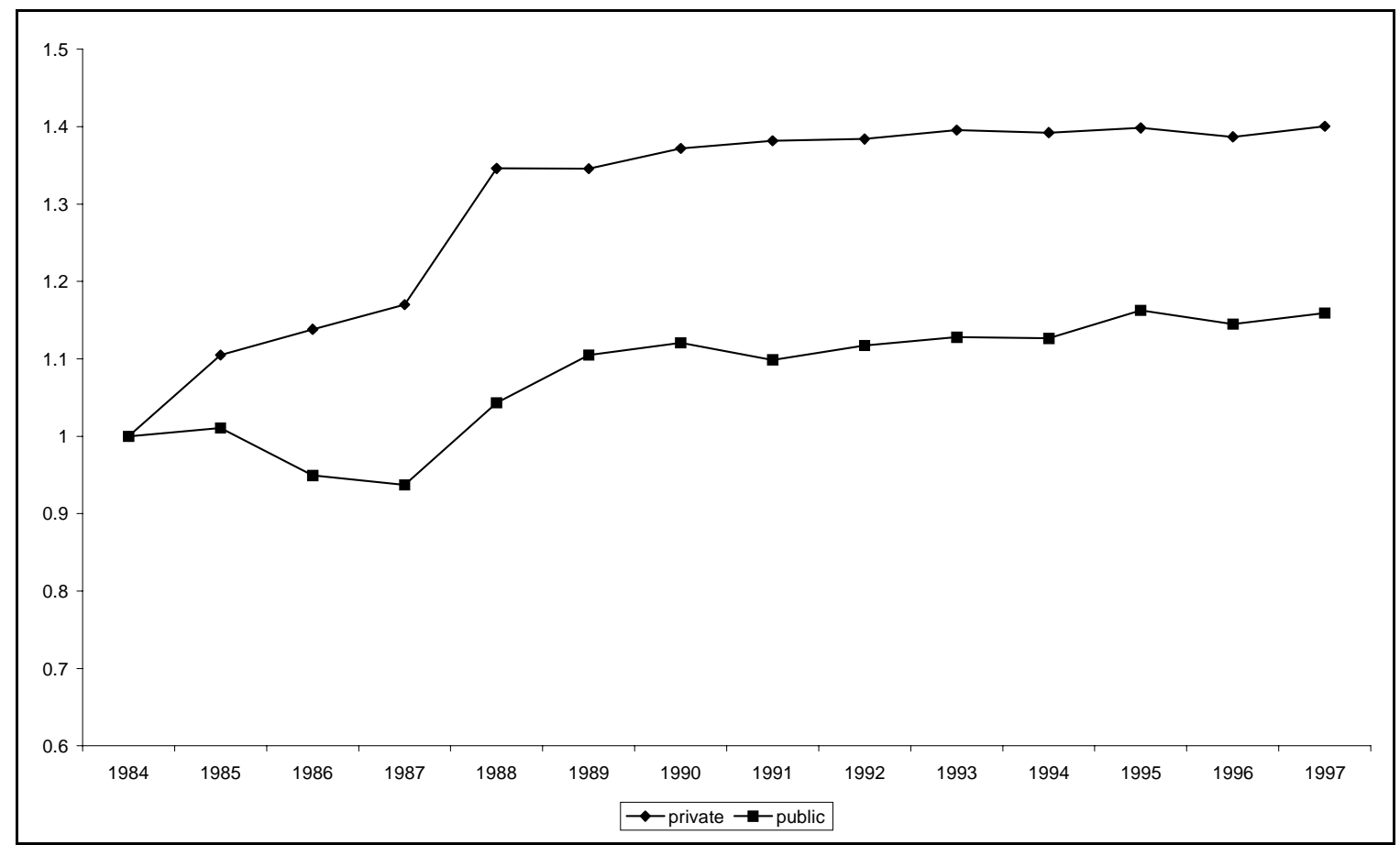

Figure 3b: Chained efficiency index (model 1)

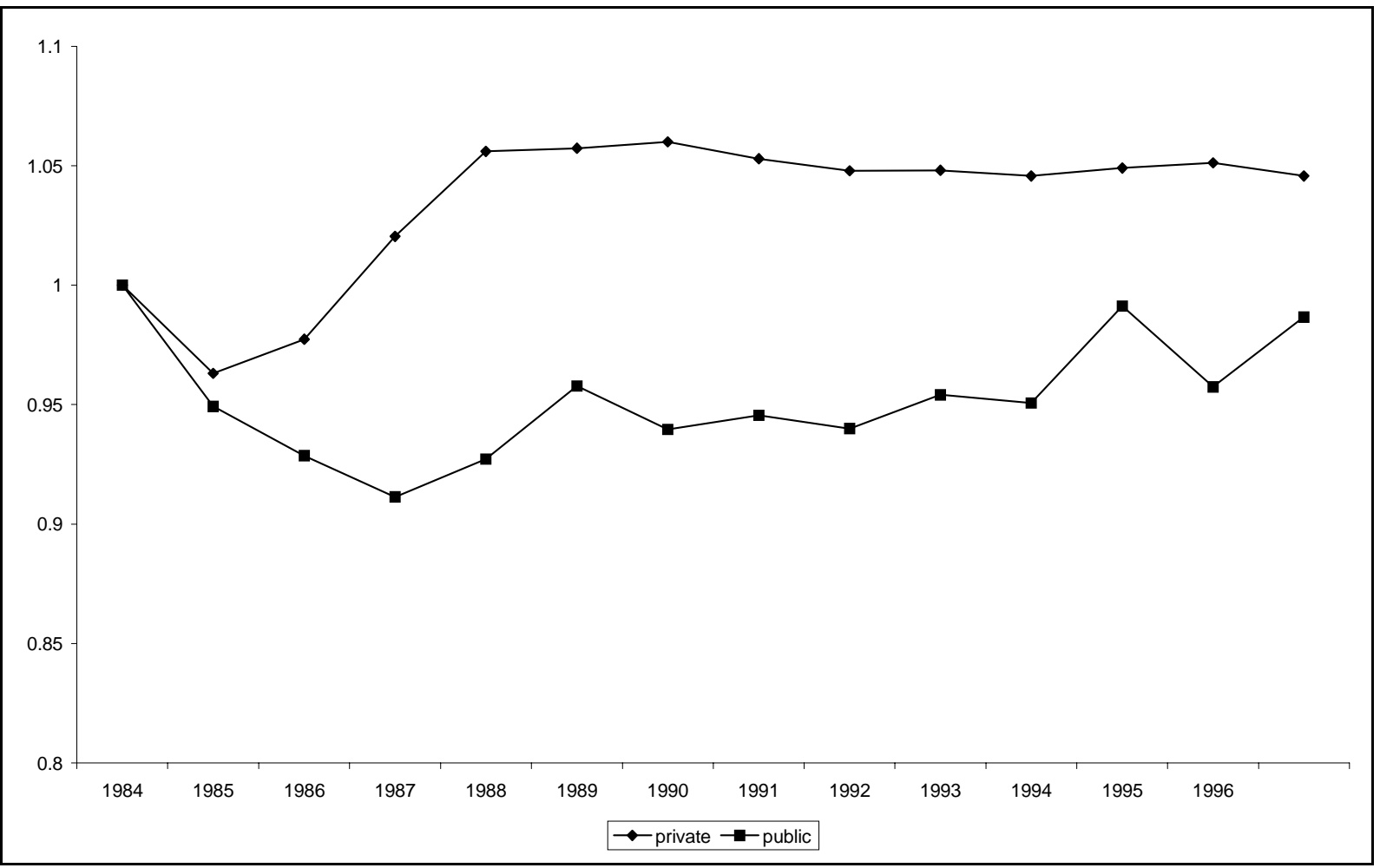


Figure 3c: Chained technological index: model 1

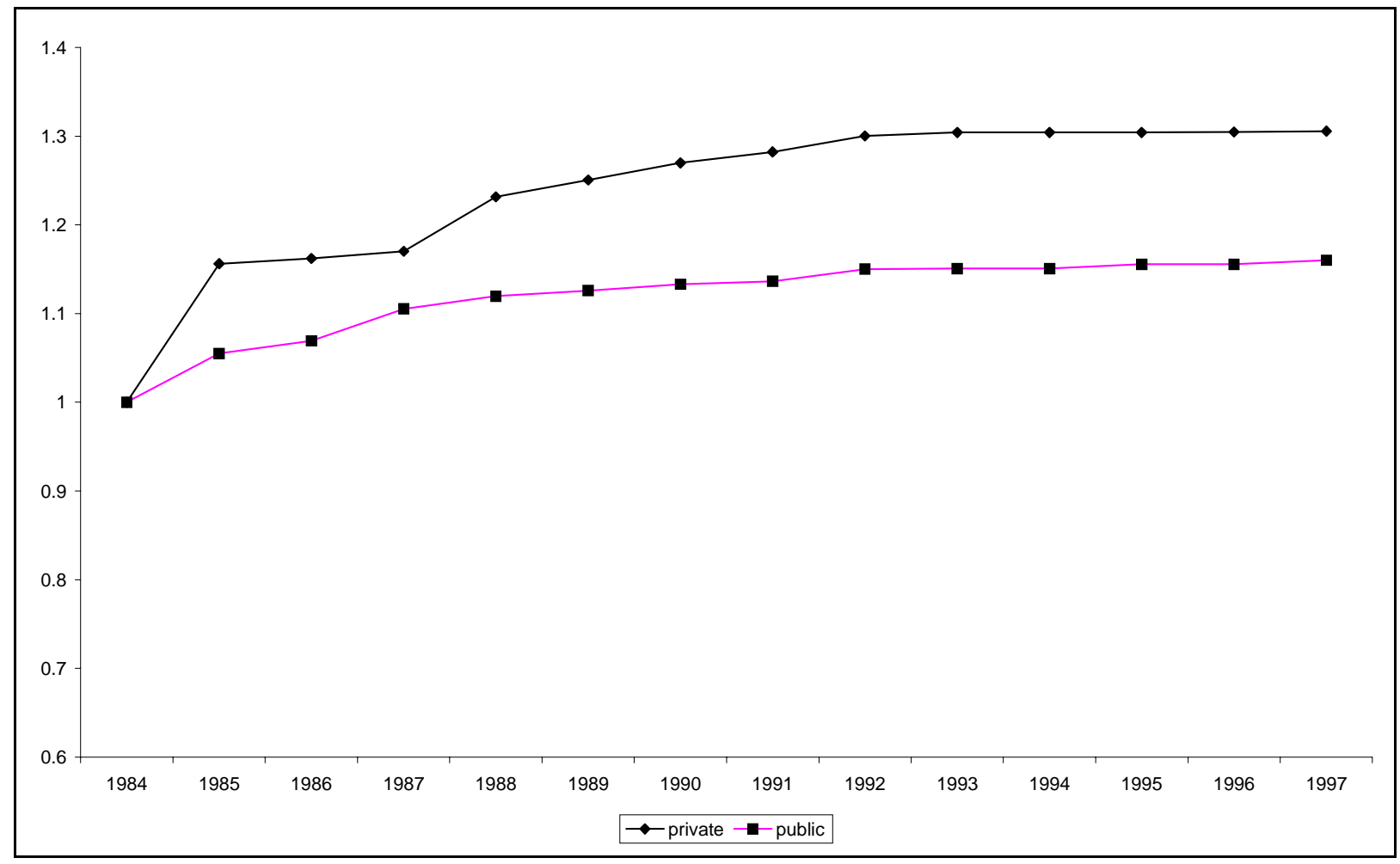

Figure 3d: Chained scale index: model 1

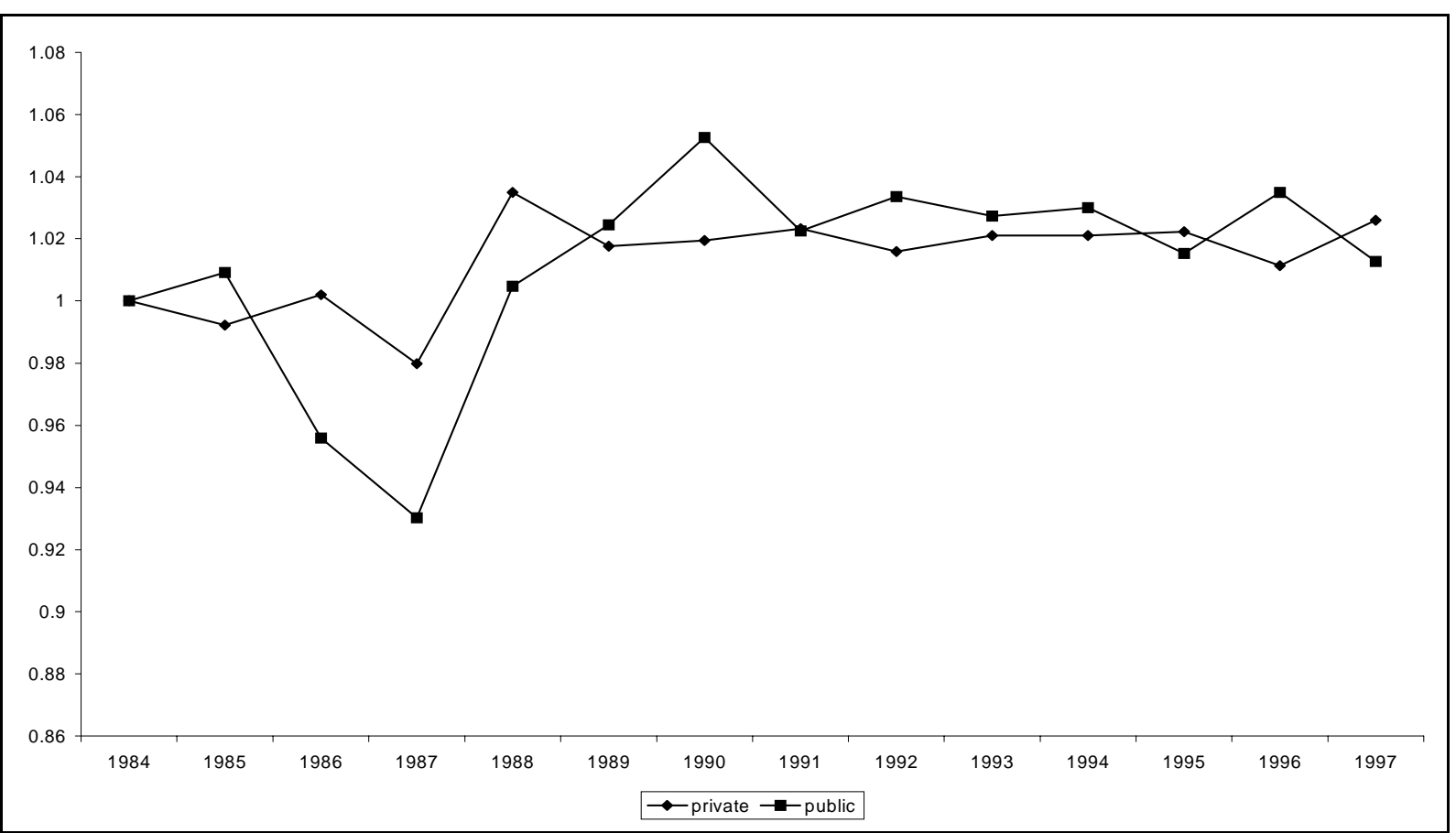


Figure 4: Efficiency scores of individual private firms

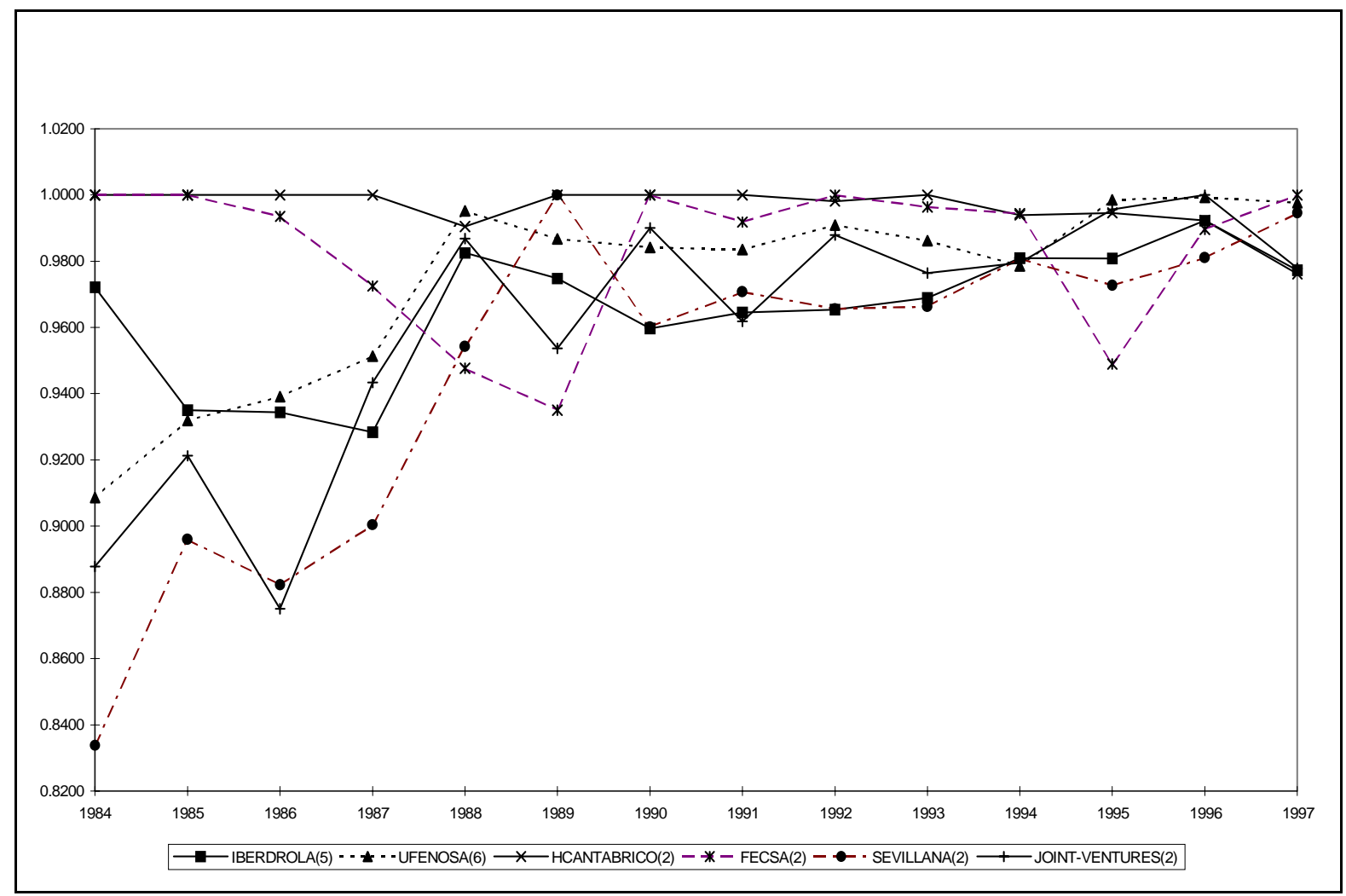

Figure 5: Evolution of structural efficiency in the public and private sectors: Model 2

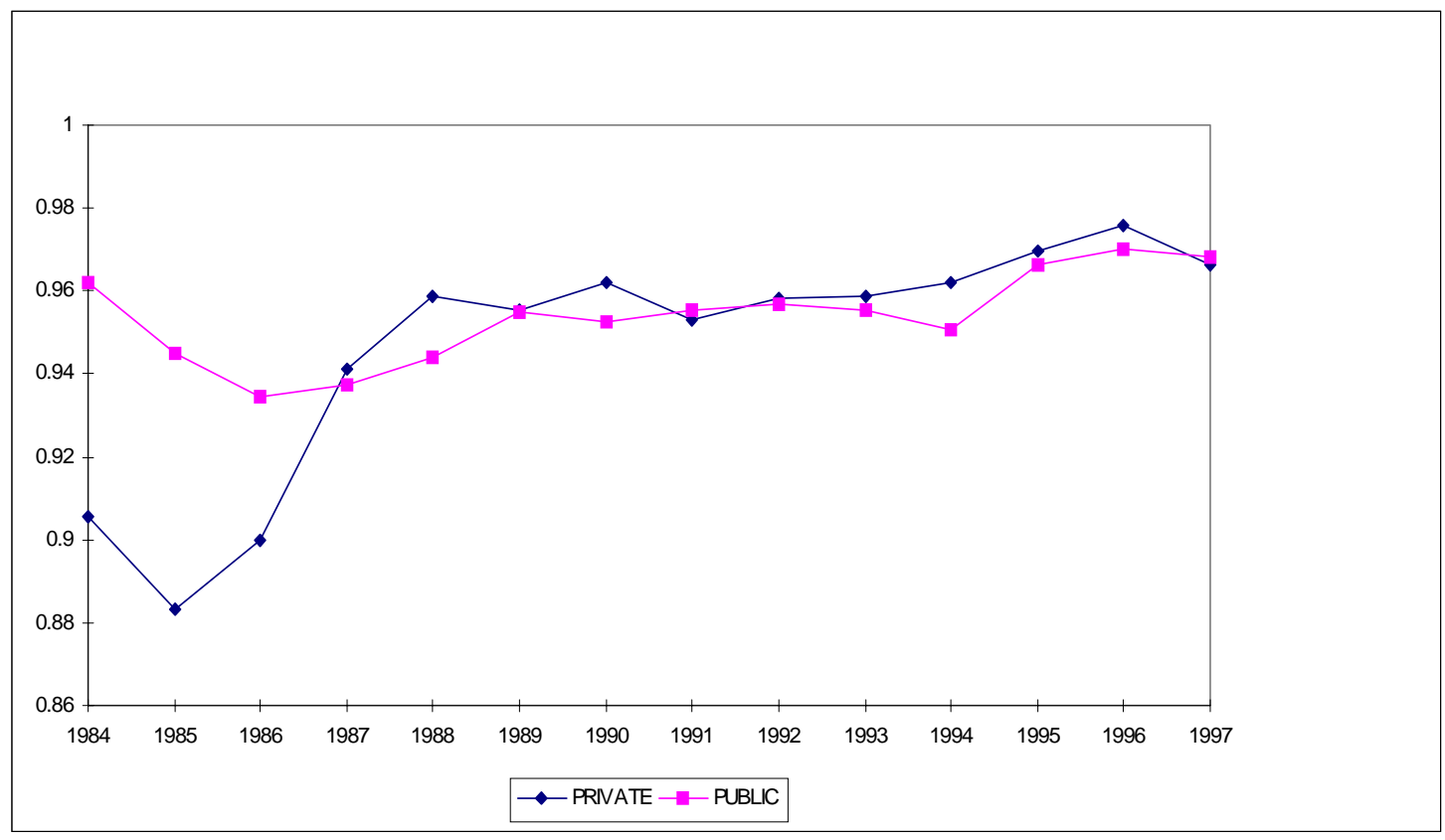


Figure 6: Effectiveness of environmental constraints and effect on output (comparison between models 1 and 3)

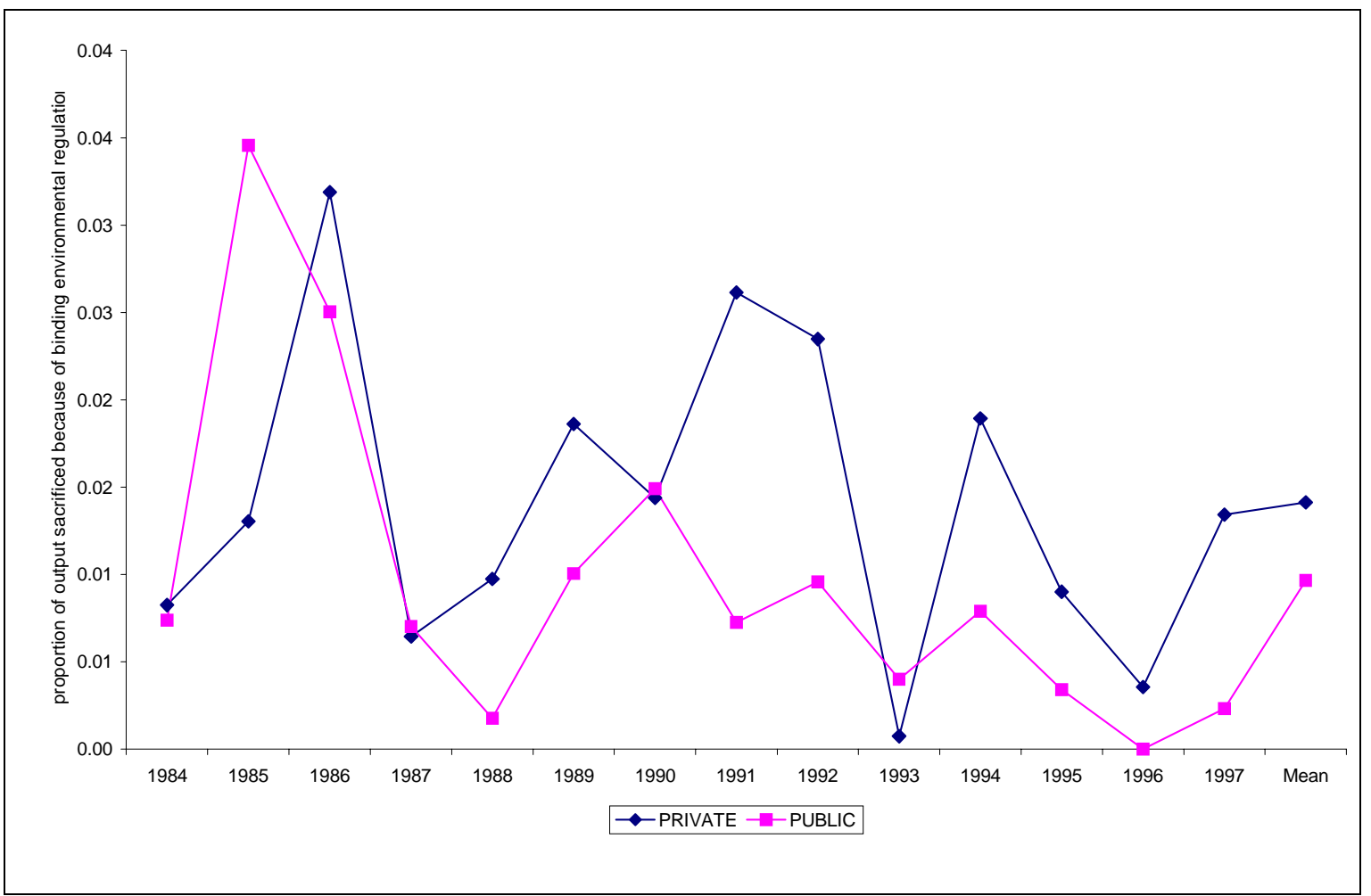

Figure 7: Evolution of Structural Efficiency in public and private sectors: Conventional model (4)

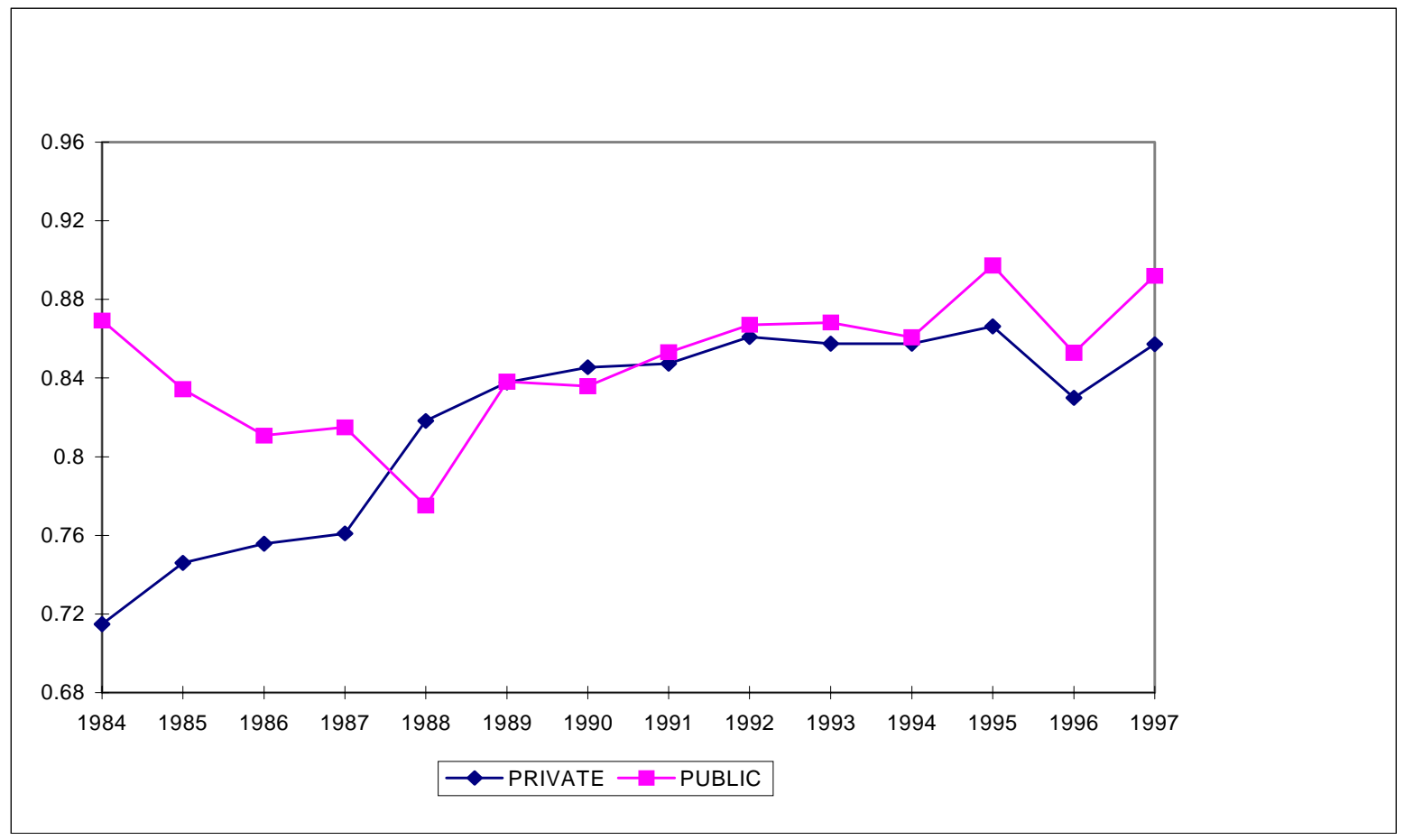

